\title{
Transforming Cities by Designing with Communities
}

\author{
Rosie Webb, Gabriela Avram, Javier Burón García and Aisling Joyce
}

\begin{abstract}
The Adaptive Governance Lab at the School of Architecture at University of Limerick has been working collaboratively with local government officials and community activists on action research projects co-designing with communities in neighbourhoods, villages and city districts in various locations in Ireland since 2010. The collaboration model developed is a genuine example of 'hackable city-making', where the local communities are involved in designing specific solutions for improving liveability in their areas, with the involvement and support of local government. A 'Designing with Communities' framework has emerged from the process in the 5 years of practice this chapter refers to. This has led to the need to refine the characterisation of the time frame, the methodologies, the commitments required from participants, the financial costs associated with the process, the advantages and disadvantages of engagement as well as the replicability of the process across cultures and governmental systems. Our chapter documents that ongoing process, defines the emerging structure of the framework, reflects on the value and risks of the process that has been carried out to date in terms of its usefulness as an urban management tool and active learning tool and proposes ways in which the framework can be adapted to fit into the developing community engagement structures of both academia and local government in Ireland.
\end{abstract}

Keywords Co-design $\cdot$ Community engagement $\cdot$ City-making Tactical urbanism

R. Webb $(\bowtie) \cdot$ A. Joyce

Adaptive Governance Lab, The School of Architecture, University of Limerick, Limerick, Ireland e-mail: rosie.webb@limerick.ie
A. Joyce
e-mail: aislingjoyce@gmail.com

\section{G. Avram}
Interaction Design Centre, University of Limerick, Limerick, Ireland
e-mail: gabriela.avram@ul.ie

J. B. García

Fab Lab Limerick, The School of Architecture, University of Limerick, Limerick, Ireland

e-mail: javi.burongarcia@ul.ie 


\section{Introduction}

Since the autumn of 2010, the Adaptive Governance Lab (AGL) at the School of Architecture at University of Limerick (SAUL) has been working in close cooperation with local government officials and community activists on action research projects, co-designing with communities in neighbourhoods, villages and city districts in various locations in Ireland.

The goal of these projects was to involve the local communities in designing and adapting specific solutions for improving liveability in their areas, with the support of local government collaborators. The current chapter focuses on the 'Imaginative Community Woodquay' project, undertaken in Galway, Ireland, between 2013 and 2015.

To achieve this goal, the AGL has developed a framework that can assist local government in supporting changes in the fabric of communities and in the natural and built environment of these places, using methodologies that have been modified to suit the objective of aligning bottom-up initiatives with top-down planning. The 'Designing with Communities' framework was developed and then improved through the experience gained working directly with community groups using innovative collaboration tools and processes.

The current chapter documents the methodology that has been developed and refined in five years of practice. We describe a framework for our interventions, connecting design-driven, bottom-up actions to top-down sustainable development initiatives, in a way that impacts not only the immediate outcomes of built environment projects, but the systems of governance themselves. Within this framework, we define parameters such as the time frame, the commitments required from stakeholders and the methodology associated with the process. In addition, we want to reflect on its advantages and disadvantages - the value and risks of the process that has been carried out to date-in terms of its usefulness as an urban management and active learning tool, and propose ways in which the framework can be replicated and adapted to fit into the developing community engagement structures of both local government and academia in Ireland.

Taken together, it is our ambition to identify the appropriate means for supporting government to become adaptive, through the incorporation of a process that aligns local creativity and experimentation with government processes, through iterative feedback loops.

Our approach combines a number of broader developments. From a top-down perspective, governments have become more interested in finding new, more inclusive ways for public consultation. Public consultation is a mechanism built into the fabric of democratic governance. Such consultations are usually organised by local authorities to explore the opinions and positions of the citizens whose lives are to be affected by future decisions related to the built environment, transport, local resources, etc. Typically, they involve the passive participation of the public once most of the detailed design decisions have been made on a project. 
In order to increase the efficacy of public consultations, local authorities are exploring new modalities of reaching out to communities and neighbourhoods, using social technologies such as forums, mailing lists, Facebook groups and pages, Twitter and others. However, these tools are there mainly for supporting coordination and awareness, and for facilitating face-to-face meetings and decision-making. At the same time, local authorities are also interested in employing tools and strategies inspired by the smart city concept (Nam and Pardo 2011) to provide better public services and more efficient governmental systems. They are becoming more adept at using digital technologies to crowdsource information related to local problems that need interventions and at using Internet-of-Things devices to target services more efficiently.

In Ireland, local government policy encourages early public engagement in identifying local needs, involving citizens directly in decision-making and data collection, to back up decision-making with evidence. Amongst Irish local authorities, a few have adopted an innovative perspective and encourage the so-called beta approaches to solving complex urban problems, relating, e.g., to the environment, to safety and street hassles, to public realm, street art (DCC Beta Projects 2013).

From a bottom-up perspective, particularly in the wake of the recent global financial crisis, citizens in many countries have been organising themselves around tactical urbanism initiatives. Tactical urbanism interventions are short-term, low-cost interventions, initiated by a range of actors including governments, businesses, citizen groups, artists, non-profit organisations or communities, and involve actively designing, building and implementing small, incremental changes to the built environment, rather than just discussing long-term strategic plans. They attempt to solve complex problems that confront the city population by creating quick and easily implemented solutions through micro-level project opportunities. Some of these interventions are sanctioned by the public authorities; some others are unsanctioned and happen in a more DIY, guerrilla manner. Saitta (2009) refers to these as 'tactical urbanism' and, respectively, informal interventions.

In the planning process itself, we have also noted a rising interest in co-creation sessions between planners and residents, involving local authorities and citizens working together to design and implement the most desirable solutions. While consultation asks people what they think about possible solutions, co-creation involves an imaginative exercise of thinking about and describing (or even building) prototypes of what could exist in the future.

Taken together, the formation of strong communities and of strong networks between public officials and members of these communities is meant to create a base for opening the city for changes, entrusting local communities to bring to life new initiatives. In their Hackable Cities Manifesto, Ampatzidou et al. (2015) speak about this kind of initiatives as 'making the city hackable'. Such initiatives encourage various stakeholders, often using digital technologies, to initiate changes that incrementally make the city more resilient and more liveable through the direct involvement of local communities. 
There has been a rise in practices in which the public is involved or involves itself directly in urban planning/city-making worldwide. Various practices (from community mapping and social media campaigns to events designed to support capacity building) assume different levels of public involvement, ranging from consultation to co-creation. The AGL acted as a facilitator for a specific local community interested in city-making to collaborate with Galway City Council and enact collective (hacking) practices. It is worthwhile noting that the local authority could not be considered an open institution before this project, and its appetite to collaborate with citizens developed during the process. With our work at the AGL, we aimed to create a framework to support these co-creation processes between local authority officials and residents that builds on the tactical urbanism interventions repertoire. This repertoire offered inspiration and encouragement to the members of the local community, who adapted some of these interventions to the local conditions.

Increasingly, innovative local government managers are encouraging tactical urbanism interventions they see as instruments for achieving sustainable urban development while working in an environment of increasingly complex regulatory and statutory systems for city-making.

The AGL sees its role as a change agent, enabling, but also challenging governmental systems to become more responsive. It supports local input that could influence the direction of action and policy. Our approach is an alternate approach to master planning, which envisages a unique outcome and tries to find a direct route to achieve that end. This alternative approach allows a number of possible futures to emerge. It can be seen as an overarching framework for experimentation and action in which similar organisations can engage, in a coordinated way, in order to make an impact on the direction of urban development and to feed back findings to assist collaborative decision-making (or governance).

The AGL is a service organisation, a civic, public interest design workshop facilitator, embracing the open-source principles - rather than having the intent of creating a product or business, although industry actors can be involved in the prototyping activities. It has a role in the cross-fertilisation of teaching and research. From a teaching perspective, it engages in training professional designers in facilitating community input into the use, design and operation of public spaces and services. In the development of new urban space solutions, innovation forms an important constituent element of the community engagement framework. Research into the collection, analysis and visualisation of local data forms another key element. Good local governance and the forging of strategic partnerships with public, private and notfor-profit agencies are at the heart of AGL's mission. From a governance perspective, the AGL works to embed design thinking and methodologies in civic governance.

In 2013, the AGL was invited to work in Galway, a city on the west coast of Ireland, with the Woodquay business and residents association and Galway City Council. The partnership developed between Galway City Council, the University of Limerick (represented by the Adaptive Governance Lab, the Interaction Design Centre and Fab Lab Limerick) and an assemblage of local actors in Woodquay, Galway, coming from various backgrounds, such as residents and business people, 
artists and craftspeople, and others connected to the area, has given us the opportunity to distil lessons learned that we share.

\section{Background}

The Adaptive Governance Lab approach was informed and inspired by the role of urban designer as 'network weaver' (Webb 2010), the tactical urbanism movement and co-creation methods that use participatory design approaches involving communities. Each of these influences is discussed below.

\subsection{The Role of the Urban Designer as 'Network Weaver' to Enable the Democratic Right to the City}

In the context of the complex systems of conflicting interests that contemporary cities are, the role of the urban designer necessarily includes that of 'network weaver' (Holley and Krebs 2002) — seen as facilitator, enabler and animator of both the built form and cultural manifestations of places. The urban designer is becoming a connector between innovators, local residents, research institutions and local governments, as well as outside partners (Webb 2010).

Holley and Krebs (2002) refer to smart communities and, in this context, to their findings concerning the building of robust, intelligent community networks. They put the emphasis on the phenomenon commonly referred to as emergence, in which local interactions lead to global patterns. Smart networks require active management, and when left unmanaged, networks result in small dense clusters with little or no diversity. These clusters are characterised by the fact that 'everyone knows what everyone else knows in the cluster and no one knows what's going on in other clusters. The lack of outside information, and dense cohesion within the network removes all possibility for new ideas and innovation' (Holley and Krebs 2002).

Most communities start as small emergent clusters organised around common interests or goals, usually isolated from each other. Without active leaders ('network weavers') who take responsibility for building a network, spontaneous connections between groups emerge very slowly or not at all. Network weaving involves: (1) relationship building across traditional divides, so that people have access to innovation and important information and (2) learning how to facilitate collaborations for mutual benefit. The culture of collaboration triggers a state of emergence, where the outcome is more than the sum of the various collaborations (Holley and Krebs 2002).

Urban designers working within local authorities must become network weavers in order to support the creation of smart community networks - as advocated in the principles of sustainable development. Unless this happens, small, common interest 
cluster organisations will fail to grow into the robust, smart community networks they have the potential to become.

In an age of declining local authority resources, universities, in their aspirations to connect developing knowledge with real-world problems and community initiatives, can play an active role in supporting the workings of government through engagement in action research projects.

\subsection{Tactical Urbanism}

Tactical urbanism is an approach to neighbourhood building and activation using short-term, low-cost and scalable interventions and policies (Lydon et al. 2012a). The term 'tactical urbanism' was inspired by a blog post describing the temporary pedestrianisation of Times Square by the New York City Department of Transport (Lydon et al. 2012b), referring to 'low-cost, un-, semi- and fully sanctioned interventions' in the built environment as 'tactical'. The first two volumes on this topic- 'tactical urbanism' 1 and 2 (Lydon et al. 2012a, b) contributed to the dissemination of information on the agents and the practices used in this type of hackable city-making, reaching wide categories of public.

Tactical urbanism initiatives make use of open and iterative development processes, put an emphasis on the efficient use of resources and rely on the creative potential unleashed by social interaction.

Urban planning has tried to create social order and growth by organising and disciplining the 'unruly and seductive' city (Cuff and Shermann 2011, cited by Fabian and Samson 2015). More and more, this top-down approach to urban planning is being questioned, and there's an opening amongst planners, architects and politicians to learn from and incorporate DIY urbanism and bottom-up approaches into urban planning processes (Fabian and Samson 2015). According to Fabian and Samson (ibid), bottom-up urban DIY design contributions aim at re-appropriating public space by listening to real-time and real-space constraints and to the different needs and hopes of the involved citizens and communities. Modern planning is largely focused on developing a symbiotic relationship between private market forces (e.g. developers or entrepreneurs) and the public sector, with planners performing mostly creative, diplomatic and exhortative roles as shepherds of the public interest (Myers and Banerjee 2005).

Finn (2014), speaking about the rights and responsibilities of the public as they relate to public space, also considers tactical urbanism from a DIY perspective. In an era when public resources are limited and participation is a compulsory requirement of effective practice in municipal planning, DIY approaches represent a viable alternative (Finn 2014).

Regarding the kind of interventions included under this umbrella term, a noteworthy example is the 'Spontaneous Interventions' exhibition of the US Pavilion at the 13th International Venice Biennale (Bureau of Educational and Cultural Affairs of the US Department of State 2012) that included interventions described as 'pro- 
visional, improvisational, guerrilla, unsolicited, tactical, temporary, informal, DIY, unplanned, participatory, open source'.

The AGL has taken inspiration from tactical urbanism approaches that focus on reclaiming shared public space for the use of people and for improving the environment. These solutions re-appropriate space that has gradually been converted from space available to people to space devoted to the movement or storage of cars, or that has become unused or unsafe due to dereliction and neglect. Interim solutions that instigate an incremental re-balancing to accommodate human activity and/or environmental diversity have been of particular interest to the AGL. Various tactical urbanism approaches and projects such as Open Street initiatives, Parklets, Intersection Repair, Better Block, Urban Farms, PopUp Gardens, Play Streets, Mobile Vendors, Imagination Playgrounds and DePaving (Lydon and Garcia 2015) have all featured as proposals in the AGL 'Designing with Communities' framework. As well as increasing the liveability, vitality and attractiveness of an area, the collaborative design and creation of these urban installations have assisted the AGL in identifying the creative agents, environmental stewards and public space caretakers who can ensure that the changes to the public space are locally informed and locally appropriated.

One of the interventions that inspired the participants brought together by AGL was Park(ing) Day, a public participatory art project, started in San Francisco in 2005 by a group of artists and urban interventionists. Park(ing) Day immediately became a worldwide viral phenomenon which has been helping people all over the world to reenvision the parking spot as a space for human use. One of the innovations that came out of Park(ing) Day was the parklet. A parklet is a sidewalk extension that provides more space and amenities for people using the street. The parklet programme, realised through a partnership between business and neighbourhood groups benefitting from rapid facilitation by local government officials, has spread to other cities in the USA and has been replicated in neighbourhoods around the world.

According to Lydon et al. (2012a), tactical urbanism is not the same as informal interventions like pop-up or guerrilla urbanism, which just appropriate a space. The goal of the tactic is to actually 'prove' to strategic decision-making levels that the temporary intervention/'hack' should lead to more permanent change in the direction of the intervention (Lydon et al. 2012a). The experience of the City of San Francisco, involved in the creation of a licensing programme for the tactical urbanism initiative dubbed 'Parklets', demonstrates how the local government was able to employ community design processes - incorporating tactical urbanism interventions- to learn, respond and adjust its mechanisms to better achieve the aims of sustainable city development. The San Francisco Parklet Manual v2.2 clearly outlines the rules for proposing, designing, building and placing a parklet, including all the stakeholders of the process, addressing transport and health and safety regulations and outlining the approval workflow (City of San Francisco 2015).

This scaling up of the process and its adoption by the bureaucratic and commercial interests has led to questions about how hacking public space can scale:

But why did scaling up a good idea have to mean ruining it? 
There is a fervent debate happening at the moment about tactical urbanism and its relationship to social equity. As a veteran practitioner of tactics, I'm also curious about their potential to catalyse long-term urban transformation and institutional change. (Bela 2015)

Bela calls the early activation process, which can seed culture, commerce, recreation and play on a site or neighbourhood prior to permanent construction, 'iterative placemaking', and he sees the process gaining traction as a tool for instituting organisational change in government systems. The method mirrors the prototyping of interfaces and devices in interaction design. (Ibid.) Looking into the future, he claims:

As the tactics of guerrilla artists become adopted into the operating procedures of city government, this draws a new frontier for further tactical action. Today's tacticians must push beyond the pop-up and the temporary and seek to hack the DNA of organisational structures themselves. (Bela 2015)

The approach of small experimental prototyping instigated by Park(ing) Day has been adopted as a strategy by city hackers and has manifested itself in a number of recent Urban Prototyping Festivals. In Singapore in June and July 2012, UP Singapore held a series of events in conjunction with the World Cities Summit. The Science Gallery at Trinity College Dublin curated an events week and exhibition 'Hack the City, Take Control' in June 2012. In San Francisco, the Grey Area Foundation for the Arts held an 'UP Festival' in October 2012, to identify replicable, affordable ideas at the intersection of public space and technology.

Since those events, 'civic hackathons' or 'coLABs' have formed and continued to prosper and their output has addressed themes ranging from health and ageing to green issues and energy efficiency to industry sectors like tourism as well as cultural, artistic and social concerns. Thousands of passionate citizens and experts from a diverse range of professional fields and industries have contributed to experimental projects to make the places they live more liveable, competitive, sustainable and just more fun.

Tactical urbanism interventions are important processes to enable the transformation of public space with maximum bottom-up input. This is because they fill the gap between the temporary, short-term programming of public space in daylong or weeklong events/festivals, and the permanency of public realm improvement projects that are usually associated with urban renewal or sustainable travel initiatives. Festivals are almost exclusively instigated by 'creatives' working in public space and are usually driven by community interest, local tradition or a deeply felt need for community. Public realm improvements, on the other hand, generally derive from a top-down governmental drive and involve limited opportunity for local engagement in the change process. This is particularly the case if they have strict time constraints and a raft of statutory and regulatory mechanisms to fulfil. In a temporal sense, urban tactics allow local actors to understand the implications of change in public space in a more substantial way than a short-term event allows and yet without the commitment required for a permanent project. In short, medium-term installations in public space allow for experimentation and feedback, both activities that are required for a system to achieve adaptivity. 


\section{Designing with Communities-The Woodquay Project}

As we have seen, co-creation projects can help to create connections between urban planning, local governance and community development. These initiatives focus on the co-creation of common urban space, on re-thinking communal and public services, as well as on creating new digital or hybrid tools for citizen participation (Saad-Sulonen and Horelli 2010). Such tools can empower people to get involved in solving urban issues. De Lange and De Waal (2013) discuss digital media technologies as a co-creation enabler, which can support peer-to-peer citizen engagement as an alternative to the institutionalised top-down or local bottom-up ways.

Inspired by the development of these three visions of city-making, the AGL has designed a framework for participatory action research projects, as an attempt to set up a process to actively manage co-design and collaboration in urban development. This process endeavours to facilitate learning and communication through flow of local information from within and introduction to diverse ideas from without, in an effort to allow innovative solutions to emerge and to prevent stagnation. We will now move on to discuss how this was applied in one of our projects in more detail.

'Imaginative Neighbourhood Woodquay' was a community design process which leads by the Adaptive Governance Lab (AGL) at the School of Architecture at University of Limerick, working together with the Woodquay Business and Residents Association and Galway City Council from 2013 till 2015.

The initiative belonged to the Woodquay Business and Residents Association, who approached the local authority (Galway City Council). The combined residents and business group were concerned about the declining residential population and the increasing incidents of antisocial behaviour. They advanced a request to revive a market in their public space on a periodic basis, with the belief that providing a better balance to the use of the public space, (almost entirely being used for vehicular traffic and parking at the time), would make the area safer, livelier and more attractive.

The Council invited the Adaptive Governance Lab — an academic research laboratory-to engage with the community and to discuss options, also involving officials working in various functional areas of the Council. Thus, the initiator was the residents and business association, who had a possible solution in mind. The Council took advantage of this opportunity to open a dialogue, and invited a third party, known for its interest in urban development and co-design facilitation skills, to lead the process.

\subsection{Evolution of the Process}

The process started in the autumn of 2013, with two weeks dedicated to a 'Designing with Communities' exercise, held in a pop-up shop in Woodquay in September and October. Rather than supporting the revival of the weekly market, the AGL 

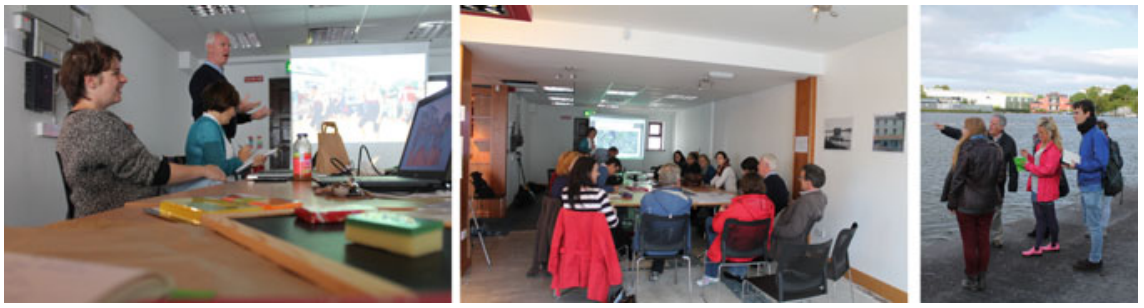

Fig. 1 Community learning day; pop-up shop; field visit

suggested a wider process, where the different stakeholders would establish a common understanding of the issues confronting the community.

Each of the two weeks consisted of community learning days-during which information was gathered from both local and official sources, and the audience (formed of locals, students, academics and representatives of the local government) heard presentations from people experienced in collaborative local planning. Community workshops and field visits were initially organised for the Woodquay Business and Residents Group and extended (by publicising them openly) to a wider public audience. These allowed the participants to listen and gain an understanding of the needs of local collaborators. Design ideas were presented at an open critique session (held as an event during European Culture Night) in Galway, to test the appetite for proposals and to get feedback. Culture Night provided a perfect format to extend the discussion beyond the local community to include those engaged on a wider scale in the social and cultural life of the city (Fig. 1).

During the first week, students from the School of Architecture at the University of Limerick (SAUL) collected data and produced strategic maps for the area, describing what existed already in Woodquay and then what could exist, making proposals for short-term interventions/temporary uses that could be executed immediately and inexpensively to catalyse the community towards fulfilling broader long-term objectives for the area. During the second week, the students designed a 'Toolkit for Streets', including street furnishing for their tactical urbanism interventions, street layouts to support them and an event programme to develop and promote emerging themes (Fig. 2).

In the spring of 2014, the Woodquay Residents and Business Association, who were an informal organisation of local home-owners and locally owned and run businesses, formed an alliance with a local Men's Sheds organisation to apply for funding from a youth and community fund. The partnership was facilitated by the City Council and was necessary as the Woodquay Business and Residents Association lacked formal articles of association to apply for funding. The group used the documentation produced during the previous AGL sessions to form the basis of the application. The funding was granted, and it was used to facilitate four events in the public space of Woodquay during 2014. These events took place in conjunction with national holidays and aimed to draw attention to the potential of the particular public space. They included a dance demonstration, a Teddy bear picnic, a street critique 


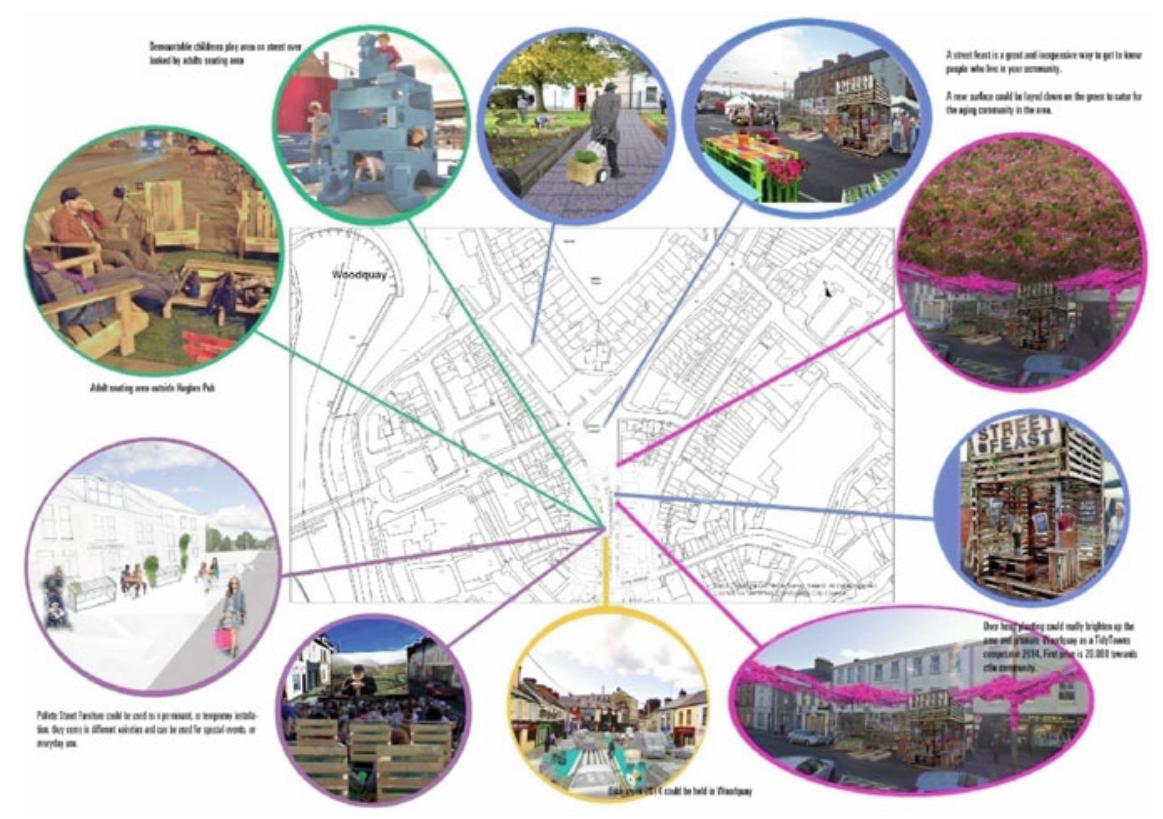

Fig. 2 Short-term interventions and temporary use layout by Luke Benson, Eimear Egan, Jennifer Hogan, Laura Pembroke, Lauren Quinn McDonagh and Orla Punch, AGL, Fall 2013

and a Christmas tree lighting event. Organising these events gave the association the chance to attract people to Woodquay and to showcase the potential of the public space.

In the fall of 2014, the AGL held two more 'Designing with Communities' weeks, involving a new cohort of students. The collaboration included a direct collaboration with Bernadette Divilly, ${ }^{1}$ a local choreographer running a participatory art project called 'Walking Wisdom Woodquay'. The project was a result of the choreographer's participation in the previous Designing with Communities weeks. Bernadette Divilly's response was informed by discussions about the research of the AGL, which revealed a predominance of older women living in the area. The students participated in investigative walks as a way of learning about how people move and engage with their public space in the area using the methodologies of the dance artist. There was a particular emphasis on the needs of the elderly female residents.

At a public critique session held at the local theatre in November, the students presented proposals for interactive street furnishings that could 'instigate the cultural and economic performance' of the place. The potential incorporation of measurement platforms (sensors, counters) into the fabric of the urban realm was an issue raised by the participants. From the perspective of the local authorities and of research groups from the local university, such interventions could assist decision-making by making

\footnotetext{
${ }^{1}$ http://BernadetteDivilly.com.
} 
the city more responsive to its citizens and enabling local actors to influence how their shared spaces develop.

The opportunity to imagine specific changes to public spaces collaboratively with community groups is a luxury few city officials can afford. One of the factors that mitigates against the practice is the fear of raising expectations of improvements that cannot be delivered due to a lack of funding. Funding for long-term improvements often comes with strict time frames for completion, which, once the statutory planning permissions and regulatory procurement procedures are adhered to, leave minimal time for public consultation. The year-long process of design thinking and community coalition building described above would need to be substantially compressed. Even with the most dedicated participants, most communities suffer from consultation fatigue when such a high level of commitment is required. Notwithstanding this issue, the cost of not engaging with community groups in the design and creation of public space forms a much greater risk to the success of public realm projects which may suffer from lack of distinctive local character and lack of local ownership of the space in terms of both its future adoption and local caretaking.

The second factor that inhibits Council officials who wish to engage in this process is the perceived role of the officials. These are often reluctant to express a personal opinion that may be at odds with an official position of which they may or may not be aware. They are also often expected by the community to solve issues that may not be within their remit. Local authorities that can have projects progressed to a point of 'shovel readiness' are best placed to avail of funding when it is announced. Asking for long-term public engagement requires a high level of trust, and no guarantee can be provided that the effort will have a direct impact on improving life in the area. That level of trust can often accumulate where local authority design professionals are engaged at local level as 'town architects', but such a role is rare in today's local governance structures. Occasionally funds become available for short-term consultancy contracts for 'artists in the community' or 'community design facilitators' through arts and cultural funding mechanisms, but these are limited in scope and duration by their nature, and not supported as long-term initiatives. The trust must be connected to the ongoing build-up of intelligence about places and the visibility of that information, analysis and consensus building, rather than being personality driven or connected to any one individual within or without the governance organisations.

In Woodquay, after the extended collaboration period, it was important for the codesign process to lead to a quick, visible and substantial intervention in the area. The decision was made in the spring of 2015, together with the community, to implement one of the student-envisaged interventions. The stakeholders chose a parklet as the most appropriate temporary intervention for Woodquay. The parklet was designed and built by summer bursary students in 2015 .

The AGL teamed up with the Fab Lab Limerick and the Interaction Design Centre at the University of Limerick to design and fabricate the parklet over a 6-week period during the summer for a demonstration project in the autumn of 2015. The plan was to have the parklet in place for a trial period, to allow the community to engage directly in the design of their public space and to provide feedback in real time. It was intended that the information gathered and the lessons learned from the 
demonstrations would influence future permanent changes in making Woodquay a more liveable place and assist the community and local authority in collaboratively identifying funding opportunities from public and semi-public sources, as well as alerting potential industry and commercial partners to worthwhile projects.

Some of the ideas for interactive installations discussed with the stakeholders were: sensitive 'musical' plants included in the parklet that would react to movement/proximity, sensitive light installation triggered only by the presence of more than one person, a hyperlocal website and newspaper, a dedicated radio/podcast station. Other ideas discussed were: collecting oral histories from locals during dedicated events or through a temporary audio booth, providing free $\mathrm{Wi}-\mathrm{Fi}$ and having a landing page dedicated to the project, having a geocache hidden in the parklet, the creation of an Ingress portal, a foursquare venue, etc.

The summer project engaged the stakeholders in the co-design, fabrication and installation of the parklet installation in the public space of Woodquay. Through the 'Designing with Communities' process, and in particular, through the presentation of emerging design proposals at weekly public critique sessions held alternatively in the local theatre in Galway and in the Fab Lab in Limerick City, the installation's shape, size and functionality were debated and negotiated with local actors, its location and placement were agreed and facilitated by Council officials and nearby business owners and residents, its design was supported, developed and refined by industry partners, maker community collaborators and university researchers, its operational and maintenance protocols were clarified, assigned and accepted by willing participants, as well as being rejected by those more reserved in their engagement.

A team of potential collaborators, including Bernadette Divilly, the choreographer who ran the participatory art project and Ed Devane, ${ }^{2}$ sound artist, declared their availability to run and curate events around the parklet installation. The design project and the participatory design process allowed to connect the aspirations of the community, to the imagination and innovation spirit of these socially engaged artists and makers. Industry partners, including the DIY department of a local building supply merchant, supported the project by donating materials and expertise. An international lighting company offered interactive lighting and sound installation elements. Academic collaborators from Galway and Dublin engaged in the project to provide research assistance in scoping pre- and post-occupancy measurement and monitoring tools and performance parameters. All this interest was in line with the AGL intention of making the parklet structure open and 'hackable', allowing the addition of new uses and functionalities.

In the autumn of 2015, AGL ran two more 'Designing with Communities' weeks in Woodquay, where new streets layouts and installations were imagined, discussed and proposed. The first week was timed to coincide with the European Culture Night and Global Park(ing) Day in September and addressed the theme of 'Street Culture' in Woodquay. The second demonstration week was held in October during Social Inclusion Week and fed into a Universal Design workshop week facilitated by the City Council.

\footnotetext{
${ }^{2}$ http://EdDevane.com.
} 

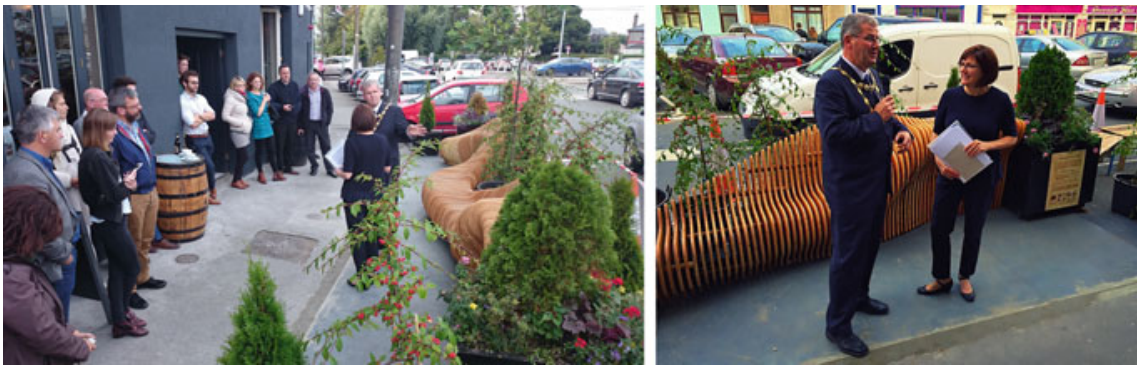

Fig. 3 Parklet in place and open critique in Woodquay

The parklet was installed in Woodquay, reclaiming a space previously used by cars for people (see Fig. 3). The plan was to go through a further iteration of the hackable parklet installation during those demonstration weeks, to discuss the need for developing a parklet licensing procedure and to develop a new urban prototype aimed at enabling accessibility to premises in the area.

However, due to the lack of a project champion at senior management level within the local authority as the director who commissioned the work had moved on and following the job transfer of the person who initially coordinated the AGL involvement, these intentions did not materialise. After these events, the parklet was dismantled and put in storage. Nevertheless, the social capital created during the 3-year span of the project remains. The Woodquay residents and business owners, as well as the wider community got a glimpse of what is possible and how can it be achieved. Business owners state that the footfall in the area has risen, students of the local university often choose the area as site for their projects, and the locals' sense of pride appears to have been restored. The conditions are now ripe for other interventions (tactical urbanism or others) in the near future.

It is worth noting that the chair of the AGL straddled the academic and local authority project champion roles, holding simultaneously a position in the City Council and teaching at the University. During the process, this situation was perceived as both an advantage and a challenge. The privilege of access to information and understanding of the structures of local government were often outweighed by the responsibility of continually reiterating the position from which one was operating.

This demonstrates that while the individual hacker attitude and the collective practices remain with the community, the 'hackability' of the institutions was temporary and depended on the presence of specific actors. The future years will hopefully bring more openness and appetite for collaboration, as communities start putting pressure on the local authorities bottom-up, and the top-down legislation encouraging co-creation emerges at national level. 


\subsection{The 'Designing with Communities' Framework}

An analysis of the work undertaken with the business and residents group in Woodquay, the local authority officials in Galway City and with the various communities of interest and local businesses who engaged in 'Imaginative Neighbourhood Woodquay' project, has led to this presentation in context of the Designing with Communities framework. Here, we will try to abstract and distil the essence of this framework, making it available for further appropriation and adaptation. These are the main characteristics of the framework:

\section{The Time Frame}

The Designing with Communities framework is conceived as a meaningful mediumto long-term (9-18 months) intervention as part of a continuous, cyclic engagement process. Based on our experience, targeted community engagement weeks lasting 3-5 days should occur 4-6 times per year, while tactical urbanism interventions should be in place for 3 months to 1 year. Feedback should be collected, analysed and changes implemented continuously during this time.

\section{The Actors}

- The 'network weaver': the process has to be led by urban design leadership (a person, an organisation, an academic research group) with good connections with and authority within the local institutions, connected with businesses and local communities; the network weaver has to be there for an extended period of time, so that he/she/they can gain the trust of the community.

- Local authority official engagement to develop and coordinate licensing/permitting approvals processes if required.

- Local community groups working together (Tidy Towns, heritage preservation groups, environmental protection groups, community gardeners, etc.).

- Education institutions - universities, technical institutes, schools, primary and secondary.

- Communities of interest, interested in DIY (such as Fab Labs, makerspaces, Men's sheds), arts and performance (socially engaged artists, radical empathy groups, etc.), special interest groups (Access for All, Smart Aging Groups, Friends of the local Park, etc.).

- Professionals (possibly as a pro-bono exercise, or as continuing professional development).

- Urban innovators (from local industry or local small and medium enterprise companies, start-ups, etc.) (Fig. 4).

\section{The Methods and Techniques}

- During Community Engagement Weeks, we found the following formats to be working well.

- Learning Days-using formats like PechaKucha style lighting talks from local actors, civic conversations with presentations and panel discussions with 'experts' and strategic and operational policy makers. 


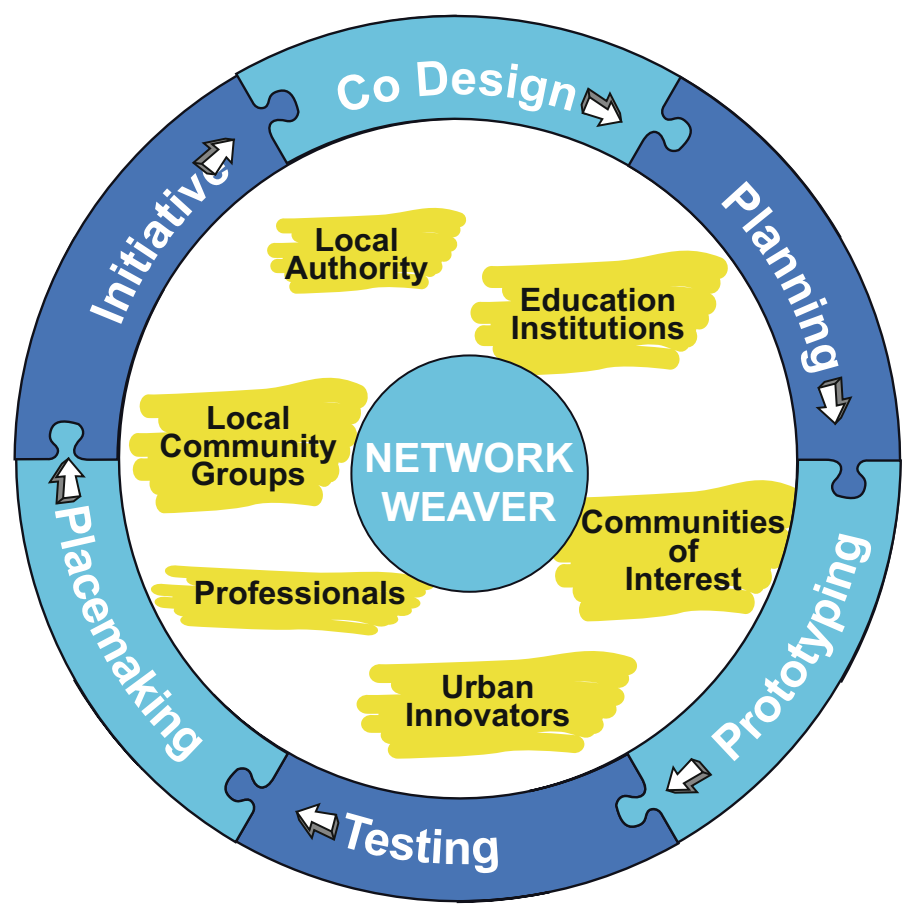

Fig. 4 Time frame and actors

- Field days and tours-led by local interest groups and officials.

- Community mapping and auditing events-crowdsourcing local and less known information, visions, aspirations, things that people treasure and things that they dislike.

- Community design workshops - exploring specific proposals, ideally with diverse and intergenerational groups (hands-on and interactive, ideally involving physical and digital modelling, drawing and narrative development). These could work with proposals for the area or specific proposals for interventions.

- Open design critique sessions - bringing together analysis of information collected about what exists currently and making proposals for tactical urbanism interventions about what could exist, to address the needed change to the built and/or natural environment in the area.

From the point of view of local government, it is increasingly difficult to find a structure within which urban designers/network weavers can operate. The lack of time and bureaucratic constraints are making long-term collaborations with local communities a difficult challenge.

One of the challenges to placemaking today is the absence of a coordinating framework for design activity. That absence is felt both at the top and from the bottom. Top-down, it is increasingly difficult to find a place for urban design professionals 
within local government structures. Simultaneously, local, amateur and professional amateur input (bottom-up contribution) are being disabled, due to increasingly onerous statutory and regulatory systems.

The Designing with Communities framework described in this chapter attempts to improve both of those situations, by defining the role of designers within a new process, which could parallel or even align with statutory local planning processes. It proposes a co-design process in which professionals and local designers can both engage. Lastly, it aims to connect these actors to each other through digital media and tools.

The Designing with Communities framework focuses on community engagement events (no comma) and the design of tactical urbanism interventions which can be imagined, refined and realised within a relatively short time period (3-6 months), with little funding (under 5,000 euro) and which, (comma added) crucially, are (not is) flexible enough to be hackable, programmable and open to be curated by others who engage in the process.

This design work must be supported by a participatory platform that would include learning days, workshops and importantly, community open critiques, which have to happen locally and, ideally, within the public space they address. The platform involves both face-to-face meetings and digital- and social media-mediated resources and conversations. The changes or design options being considered have the aim of improving the shared public spaces, safety and liveability of the area, but neither their physical nor their operational aspects can be predetermined. Therefore, flexibility is required in developing the options as they emerge. In a truly participatory approach to design, solutions must be allowed to evolve with local input and with an explicit agenda to facilitate change.

\section{Advantages and Disadvantages}

There are obvious advantages resulting from the application of the framework. A main advantage of the process that has been carried out to date has been its capacity to move public consultation from a broadcast mode to a genuine conversation about the design of shared public spaces. Through the period of engagement in the codesign process, the conversation in Woodquay changed from 'Reasons why a public bench will adversely affect locals by attracting antisocial behaviour' to 'Where can we place a public bench to get the most benefit for all and how should it be designed to make the place more attractive, provide for the most vulnerable users and to attract pro-social behaviour?'.

The process created a valuable platform to allow socially engaged actors to emerge and to have a voice regarding the use of public spaces. Co-creation provided opportunities for cooperative direct action. The incremental change facilitated by the 'Designing with Communities' process makes the actors feel more comfortable with the environmental changes, due to their perceived reversibility, and to accumulation of an evidence base to either reject or support the interventions for the future.

There is also a potential risk of using the process as an urban management tool: if consensus cannot be reached, there is a danger of leaving public realm improvements in a perpetual temporary state. Another risk is that the co-design process produces a 
poor-quality outcome, as a result of 'design by committee'. Sound design leadership should mitigate against these risks.

\section{Replicability}

For the 'Designing with Communities' framework to fit into the developing community participation structures of both academia and local government, there is a need for cross-institutional governance structures, detailed time frames and multi-annual funding mechanisms. The citizen innovation and urban prototyping exercises need to engage directly with local small and medium enterprises for the products and services imagined to develop real value for the community.

The process is outgrowing its current format, which is situated within the academic term schedule and allows for only two of these design weeks with the same group of junior designers. It is expanding both in terms of the time commitment to encompass year-long participation, and in terms of the skill base of the participants, opening out to related disciplines (interaction design, digital fabrication, applied electronics).

The AGL is increasingly committed to making, as well as designing, and is working intimately with digital fabrication experts and interaction designers in the areas of digital local manufacturing, digital platform design, digital mapping processes and environmental sensors. The AGL is finding a lot of common interest in Living Labs networks dedicated to co-design and citizen innovation and is positioning itself in this field of expertise. We are now working towards finding ways in which the framework we have developed could be adapted to fit into the developing community engagement structures of local government in Ireland. We hope that by doing this, a strong link between community planning and official governmental planning processes can be created.

\section{Implications and Recommendations on Conditions for Governance}

Flexibility is the aspect that makes the process so difficult to fit into governmental and political systems in particular, as far as capital works programmes are concerned. The process is continuous and iterative, involving a 1/2-3-year cycle to make proposals, develop strategies and enable their realisation. This time frame, in a context of capital funding regimes which, to a large extent, happen within a one-year time frame, requires an extended commitment from all those involved on a provisional basis, where no guarantee can be given for the availability of funding mechanisms as consensus develops on agreed areas for development. The fact that funds for projects and for making physical alterations are available only to the local authority operational teams through sectoral/departmental funding mechanisms (i.e. roads, housing, access, parks), rather than being allocated on a place-based approach, is also an obstacle to coordinated cross-departmental commitment. Alternate funding sources for interventions can come from other types of projects, donations and even bottom-up crowdfunding. 
The local authority itself must be comfortable with exposing the current operational systems and solutions to public critique. Citizens and communities must also be willing to operate in a climate in which the results of their time and energies investment cannot be predetermined, nor can outcomes be guaranteed. The involvement of universities is also constrained by the structure of the academic year, and any type of activities involving students as junior urban designers has to be carefully planned and executed.

An approach to solving complex urban problems centred on facilitating, enabling and supporting smart citizenship involves primarily an investment in time and human resources over monetary investment. In fact, the biggest dangers to participatory design processes are the imperative to spend money quickly, without sufficient time to allow co-design solutions to emerge, and the underinvestment in supporting dedicated 'network weavers' to facilitate and coordinate community involvement.

Just setting up a co-design framework or programme to facilitate bottom-up input is not enough. This needs to be matched to institutional processes and managed by designers working from within the structures of government, forming relationships at a local level directly with local residents, businesses, artists, craftspeople, activists, as well as with academia and representatives of other public services and bodies.

The co-design process is primarily concerned with facilitating democratic decision-making. Although focused on the design of temporary installations, it equally and significantly involves supporting meaningful interactions with places in general, and the street furnishings in particular as an integral element of the design. Such interactions are situated in the overlapping areas of concern for people, place and technology and are the object of study for urban informatics (Foth et al. 2011) and Urban Interaction Design (Smyth et al. 2013).

The devised process involves a concerted attempt to attract and engage local artistic and creative expression, from Urban Prototypers to socially engaged artists, from Craftivists to Community Cultivators. During the process, designers draw upon already established networks of their own, as well as reaching out to established and emerging groups in the local area. Through the design of the installations, the coordination and curation of the programme and content for their use, the identification of partners and the producing of the events associated with their collaborative design, fabrication and installation, the projects provide the opportunity to advance a public discussion about the participatory design and making of public space, and its potential to promote social capital, social cohesion and social equity. The co-design process is centred on the goal of making the urban management structures, and in particular the allocation and treatment of the public realm, more transparent, participatory, more inclusive and as a result, more democratic and equitable.

\section{Conclusion}

The case presented in this chapter emphasised the value of design processes in facilitating, managing and enabling systemic change. Also, our 'Designing with Commu- 
nities' framework proposes one specific type of intervention as a means of initiating place-based networks. The interdisciplinary nature of development and the increasingly bottom-up functioning of democracy has brought about a new model for urban management which involves, at its heart, cooperative design methodologies to guide the shift from the institutional to the collaborative model of decision-making and to facilitate the cooperative development of the built environment of places.

The value of small experimental prototyping as an operational tool for city management is well reflected in the process we followed. The most important outcome, we believe, are the networks and trust that were built through this process, allowing local authorities' representatives, urban designers, representatives of the residents and businesses in the area to have an extended public conversation about the future of the area. The conversation was also open to civic activists, artists, makers, industry partners and anyone interested. The 'Designing with Communities' participatory design process acted as a framework to connect the aspirations of the community to the imagination and innovation of these other local actors. It offered a concrete example of making the city hackable, where top-down and bottom-up were combined through 'network weaving', facilitation and animation, linking the needs of the community to high-level, official objectives.

The AGL played an important role in the process, scheduling events, inviting people, involving everyone in the conversation. As mentioned before, the chair of the AGL straddled the academic and local authority project champion roles, situation that gave her access to people, information and resources and allowed her to act as an authentic network weaver. Through this process, local residents, business owners, artists and hackers came together and began collaborating, building what Holley and Krebs (2002) call smart communities_-interconnected, emergent, dynamic and long-term. This also created the conditions for the emergence of peer-to-peer distributed networks (De Lange and De Waal 2013), e.g. via mailing lists, Facebook groups and Twitter. Fundamentally, the co-design process is about enabling a shift in decision-making from hierarchical institutions to these smart, self-organised, cooperative communities.

Our conclusions on the processes carried out to date and the unexpected continuing length and commitment of that engagement aligns with the observations regarding Participatory Action Research as expressed by Foth and Brynskov:

This leads us to a first conclusion about urban interaction design of civic technologies: They need time and resources to develop and mature in a specific cultural context. They cannot be developed and figured out in a vacuum, they need to be grown, as it were. Organicity is impossible to plan. We have known for a long time that community development is about 'human horticulture' rather than social engineering. (Foth et al. 2015) 


\section{References}

Ampatzidou, Cristina, Matthijs Bouw, Froukje van de Klundert, Michiel de Lange, and Martijn de Waal. 2015. The hackable city: A research manifesto and design toolkit. Amsterdam: Amsterdam Creative Industries Publishing.

Bela, John. 2015. Hacking public space with the designers who invented Park(ing) Day. Next City. http://nextcity.org/daily/entry/hacking-public-space-designers-parking-day. Accessed 1 June 2015.

Bureau of Educational and Cultural Affairs of the US Department of State. 2012. Spontaneous interventions. http://spontaneousinterventions.com/. Accessed 7 June 2016.

City of San Francisco. 2015. San Francisco Parklet Manual 2.2. http://pavementtoparks.org/wpcontent/uploads//2015/12/SF_P2P_Parklet_Manual_2.2_FULL1.pdf. Accessed 10 Apr 2017.

DCC Beta Projects. 2013. 6 Themes. Dublin city council beta. https://dubcitybeta.wordpress.com/ 2013/11/18/6-themes/. Accessed 16 Aug 2016.

de Lange, Michiel, and Martijn de Waal. 2013. Owning the city: New media and citizen engagement in urban design. First Monday 18 (11).

Fabian, Louise, and Kristine Samson. 2015. DIY urban design—Between ludic tactics and strategic planning. In Enterprising initiatives in the experience economy: Transforming social worlds, ed. Britta Timm Knudsen, Dorthe Refslund Chrisensen, and Per Blenker, 38-59. New York: Routledge.

Finn, Donovan. 2014. DIY urbanism: Implications for cities. Journal of Urbanism: International Research on Placemaking and Urban Sustainability 7 (4): 381-398.

Foth, Marcus, Jaz Hee-jeong Choi, and Christine Satchell. 2011. Urban informatics. In CSCW'11 proceedings of the ACM 2011 conference on computer supported cooperative work, 1-8. New York: ACM.

Foth, M., M. Brynskov, and T. Ojala. (2015). Citizen's right to the digital city: Urban interfaces, activism, and placemaking (1st ed.). Springer.

Krebs, Valdis, and June Holley. 2002. Building smart communities through network weaving. http:// www.orgnet.com/BuildingNetworks.pdf. Accessed 10 June 2015.

Lydon, Mike, and Anthony Garcia. 2015. A tactical urbanism how-to. In Tactical urbanism, 171-208. Washington, D.C.: Island Press.

Lydon, Mike, Dan Bartman, Ronald Woudstra, and Aurash Khawazard. 2012a. Tactical urbanism—Short-term action—Long-term change. Miami; New York: The Street Plans Collaborative.

Lydon, Mike, Dan Bartman, Tony Garcia, Russ Preston, and Ronald Woudstra. 2012b. Tactical urbanism short-term action long-term change 2. Miami; New York: The Street Plans Collaborative.

Myers, D., and T. Banerjee. 2005. Toward greater heights for planning: Reconciling the differences between profession, practice, and academic field. Journal of the American Planning Association 71(2): 121-129.

Nam, Taewoo, and Theresa A. Pardo. 2011. Smart city as urban innovation: Focusing on management, policy, and context. In ICEGOV'11 proceedings of the 5th international conference on theory and practice of electronic governance, ed. E. Estevez and M. Janssen, 185-194. New York: ACM.

Saad-Sulonen, Joanna, and Liisa Horelli. 2010. The value of community informatics to participatory urban planning and design: A case-study in Helsinki. The Journal of Community Informatics 6 (2). http://ci-journal.net/index.php/ciej/article/view/579/603. Accessed 28 Sept 2016.

Saitta, Eleanor. 2009. Playing with the built city. https://dymaxion.org/talks/2009-26C3-built.pdf. Accessed 21 Apr 2017. 
Smyth, Michael, Ingy Helgason, Martin Brynskov, Ivica Mitrovic, and Gianluca Zaffiro. 2013. UrbanixD: Designing human interactions in the networked city. In CHI EA'13 CHI'13 extended abstracts on human factors in computing systems, 2533-2536. New York: ACM.

Webb, Rosemarie. 2010. Developing a living city process: An architect's approach to enabling interdisciplinary practice in infrastructure development. RMA dissertation, University of Limerick.

Rosie Webb is the Senior Architect at Limerick City and County Council and Head of Urban and Village Renewal. She leads programmes of work to stimulate and consolidate the historic centres of Limerick City, its towns and villages. She provides strategic vision and plan implementation using projects, programmes and initiatives dedicated to placemaking and physical development. She is a Member of the Royal Institute of Architects of Ireland, a Registered Architect in the State of Illinois, and is accredited in historic building conservation. She lectures at the School of Architecture at University of Limerick and founded the Adaptive Governance Lab at SAUL in 2010. Her research at the AGL focuses on testing new ways to build strong community networks for greater citizen involvement to influence the design and operation of shared public spaces. Rosie is Lighthouse City Manager for Limerick's joint 2018 application to the H2020 Smart Cities and Communities bid '+CityxChange', and she acted as the Limerick Manager for the URBACT III 'Techtown' Project from 2016 to 2018 and participated in the EU Transport and Urban Development COST Action Network 'People Friendly Cities in a Data Rich World' from 2013-2017.

Gabriela Avram is Lecturer in Digital Media and Interaction Design, senior researcher at the Interaction Design Centre of the University of Limerick (Ireland) and an active member of the Adaptive Governance Lab. Building on a Computer-Supported Cooperative Work and Knowledge Management background, her current research focuses on the design and development of technologies for civic engagement in urban communities. In parallel, she is also working on designing interactive technologies for cultural heritage settings with an emphasis on co-design. Gabriela has worked on numerous international research projects on topics such as adult learning, cultural and social aspects of collaboration, distributed work practices, open-source communities, and the adoption and uses of social media for work-related purposes in various environments. Currently, Gabriela is the chair of the COST Action CA16121 From Sharing to Caring: Examining SocioTechnical Aspects of the Collaborative Economy that she initiated in 2016. Gabriela has published extensively in international conferences and journals. For a complete list of publications, check her personal website at http://coniecto.org.

Javier Burón García is Lecturer in the School of Architecture, University of Limerick and the director of Fab Lab Limerick. In 2012, founded Fab Lab Limerick, a digital fabrication laboratory part of the School of Architecture. His research focuses on the role of the creative industries in local socio-economic development, the use of personal digital fabrication in architecture, and the impact of open-source technologies and participatory processes in design. He is a member of the Limerick URBACT Local Group, member of the Digital Leaders Network for Limerick Digital Strategy, member of the board of directors of Fab Foundation Ireland and Irish ambassador for the European Maker Week. He has collaborated with the EU Policy Lab of the Joint Research Centre of the European Commission. He is also co-founder of Colaborativa.eu, a creative studio exploring new ways of making digitally, new ways of working creatively and new ways of sharing collectively.

Aisling Joyce graduated from the School of Architecture, University of Limerick in 2012. In 2014, she began her involvement with the Adaptive Governance Lab and has been actively engaged as a Teaching Assistant ever since. Aisling holds a keen interest in collaborative urbanism and has explored this subject area in number of European Cities during her time as a European 
Researcher with COST EU under the Action 'People Friendly Cities in a Data-Rich World'. She currently works as an Architect in the Office of Public Works while concurrently undertaking a postgraduate diploma course in Project Management at Trinity College Dublin.

Open Access This chapter is licensed under the terms of the Creative Commons Attribution 4.0 International License (http://creativecommons.org/licenses/by/4.0/), which permits use, sharing, adaptation, distribution and reproduction in any medium or format, as long as you give appropriate credit to the original author(s) and the source, provide a link to the Creative Commons license and indicate if changes were made.

The images or other third party material in this chapter are included in the chapter's Creative Commons license, unless indicated otherwise in a credit line to the material. If material is not included in the chapter's Creative Commons license and your intended use is not permitted by statutory regulation or exceeds the permitted use, you will need to obtain permission directly from the copyright holder. 